"This paper is a postprint of a paper submitted to and accepted for publication in [IET Renewable Power Generation] and is subject to Institution of Engineering and Technology Copyright. The copy of record is available at the IET Digital Library". 


\title{
Experimental study of static and dynamic behaviours of cracked PV panels
}

ISSN 1752-1416

Received on 22nd March 2019 Revised 15th August 2019 Accepted on 3rd September 2019 E-First on 21st November 2019 doi: 10.1049/iet-rpg.2019.0359 www.ietdl.org

\author{
Mohammad Al-Soeidat ${ }^{1,2} \bowtie$, Tian Cheng ${ }^{1}$, Dylan Dah-Chuan Lu'1, Vassilios G. Agelidis ${ }^{3}$ \\ ${ }^{1}$ School of Electrical and Data Engineering, University of Technology Sydney, Sydney, Australia \\ ${ }^{2}$ Department of Electrical Engineering, Al Hussein Bin Talal University, Ma'an, Jordan \\ ${ }^{3}$ Department of Electrical Engineering, Technical University of Denmark, Lyngby, Denmark \\ 凶E-mail: mohammad.r.al-soeidat@student.uts.edu.au
}

\begin{abstract}
Solar cell power performance is greatly affected by two critical factors ageing and crack. In order to mitigate their negative effects on the solar system, these cells are to be substituted by new cells, thus, replacing the panels. This study presents an active crack detection method that detects the cracked cells within a solar string by using AC parameter characterisation without a need to have a physical inspection. The mathematical module of the solar cell shows that it constitutes of series and parallel resistors in addition to a parallel capacitor and that their values change by ageing and crack. In addition to studying the effects of the crack on the solar cell, it is verified by the experiment that the solar cells behave as a capacitive circuit, and their capacitance increases when the cell gets cracked, getting higher as the crack becomes more serious. The experiment is extended to investigate the effect of series and parallel PV strings, which are affected by cracked and partially shaded cells to evaluate their criticality levels. By monitoring the AC parameter of the solar cell and the change of the capacitance, it is easy to detect the crack when it occurs.
\end{abstract}

\section{Nomenclature}

$P_{\mathrm{mpp}} \quad$ solar cell power at the maximum power point

$I_{\mathrm{sc}} \quad$ solar cell short circuit current

$V_{\text {oc }} \quad$ solar cell open-circuit voltage

$I_{\mathrm{ph}} \quad$ solar cell light-generated current

$D_{\mathrm{f}} \quad$ forward-biased diode

$R_{\mathrm{sh}} \quad$ Shunt resistance

$R_{\mathrm{S}} \quad$ series resistance

$C_{\mathrm{p}} \quad$ parallel capacitance

$I_{\mathrm{sc} ; n}$ short-circuit light-generated current at the nominal condition

STC standard testing condition (nominal condition)

$K_{i} \quad$ temperature coefficient of the short circuit current

$T \quad$ temperature

$T_{n} \quad$ temperature at nominal condition

$G \quad$ irradiance

$G_{\mathrm{n}} \quad$ irradiance at nominal condition

$V_{\mathrm{t}} \quad$ diode thermal voltage

$k \quad$ Boltzmann's constant

$q \quad$ electron charge

$N_{\mathrm{s}} \quad$ number of series cells

$I_{\mathrm{d}} \quad$ diode current

$I_{0} \quad$ diode reverse saturation current

$n \quad$ ideality factor of the solar cell diode

$I_{\text {sh }} \quad$ Shunt resistance current

$I_{\mathrm{pv}} \quad$ solar cell current

$Z \quad$ impedance

$\omega \quad$ angular frequency

$C_{\mathrm{d}} \quad$ diffusion capacitance

$C_{\mathrm{t}} \quad$ transition capacitance

$b \quad$ constant depends on the solar cell

$V_{\mathrm{j}} \quad$ junction voltage

$V_{\mathrm{a}} \quad$ applied voltage

$A \quad$ area of the solar cell

$\epsilon_{0} \quad$ permittivity of free space

$\epsilon_{\mathrm{r}} \quad$ permittivity of the solar cell material

\author{
$N_{\mathrm{D}} \quad$ doping concentration for $n$ region \\ $N_{\mathrm{A}} \quad$ doping concentration $p$ region \\ $N_{i} \quad$ intrinsic concentration of electrons and holes for the base \\ semiconductor \\ $\tau \quad$ minority carrier lifetime.
}

\section{Introduction}

With the increasing penetration of solar photovoltaic (PV) in the energy market, its performance and reliability become critical. PV panels are considered as relatively reliable components with long service life as compared with their interfaced power electronics circuits. Moreover, most of the manufacturers provide a considerably long term output power warranty, which guarantees within the warranty period that the output power of the solar panel would be no $<80 \%$ of minimum 'Peak Power Standard Test Conditions'. For example, Sharp Mono: NURC300 has a warranty period of 25 years [1], all solar panels from Solar Technology International Ltd have 20 years [2], etc. However, some recent work claims that significant power losses are induced by the microcracks due to power mismatch among the cells on the string, which significantly reduces the power efficiency of the panel and shorten its lifespan [3]. In some cases, the micro-crack effect outweighs the power mismatch issue, and it may cause undesirable heat for the power dissipation regions. This excessive heat may lead to melting of solder joints and damage of the PV cell. The conclusion is obtained from 10 PV panels (Panel Model: Romag SMT6 (60)P PV Modules with 25-year power output warranty) for a seven-year operation at the University of Huddersfield, United Kingdom [4]. The measured efficiencies of the two degraded panels with defects are 80.73 and $85.43 \%$, while the efficiencies of other normal panels are between 97 and $99 \%$. The panel with efficiency at $80.73 \%$ indicates that it is approaching its end-of-life, which is much shorter than the expected long lifespan.

Based on this concern, the micro-cracks failure mechanisms and impact are reviewed in $[3,5-10]$. The cracks are most likely generated during the manufacturing, transportation and installation stages, and the mechanical stress such as snow loads could increase the possibility to develop a larger crack [5]. It is also mentioned in [6] that, the direct impact of the micro-cracks on the solar panel is 


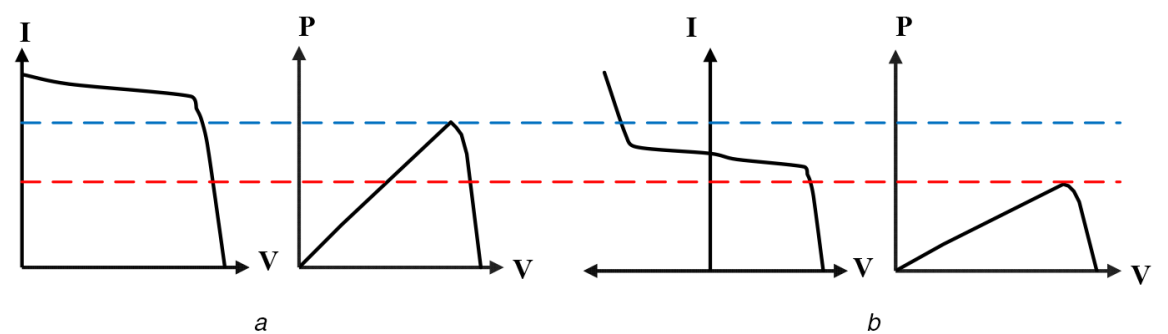

Fig. $1 I-V$ and $P-V$ curves

(a) Normal panel, (b) Same panel with one cell cracked

limited and no loss occurs when the separation area due to microcracks is under $8 \%$. However, if the inactive area continuously grows with the cracks to around $12-50 \%$, the power losses increase almost linearly. Load tests are conducted in [7, 8], aiming at evaluating the criticality of different types of cracks, and predicting the losses caused by them and their propagation, respectively. A high criticality is considered if a crack has high possibility to form an electrically isolated area of 16-24\% potentially in [7]. Results in [8] indicate that cracks do not necessarily cause electrical isolation, and loosening of electrical connection can be observed when the cell is under stress. The connections, however, may be recovered after the stress is removed for some types of cracks. Both the results in $[7,8]$, indicate that cracks occurred in parallel to the busbar are the most critical ones among several types of cracks, which not only have high probability to form an electrical disconnection but also have high degradation percentages. In [10], an investigation of the impact of the snail trail phenomenon and the micro-cracks on the solar panels is presented. The study concludes that micro-cracks play a more significant role in the degradation of solar panel performance. The decayed panel performs a lower maximum power point (MPP) than the value indicated in the datasheet due to reduced generation current.

The aforementioned research reviewed the failure mechanism, detrimental effects, criticality, and potential risks of cracks on PV panels. The evaluations in most of the above work in [3, 5-10] are through using the $I-V$ and $P-V$ curves to indicate the output power generation capability, which is the static behaviour of PV panels. An alternative is to use impedance spectroscopy [11-15], which reflects the dynamic behaviour of a cracked PV panel. In [11], the dynamic impedance of a PV module is derived and verified, which shows dependency on bias voltage and frequency. In [12], a comprehensive PV cell model is proposed, and the cell under reverse-biased condition is analysed particularly by measuring both $I-V$ curve and impedance. It is found that the partially shaded or faulty cell becomes reverse biased and forms a hot-spot which will degrade the cell performance. In [14], a method which uses dynamic impedance of a PV string to detect hot spots is proposed. Changes of high-frequency AC capacitance and low-frequency DC resistance are compared. In [15], impedance spectroscopy is used to detect faulty and degraded PV cells, such as mechanical stress and PV cells with interconnect ribbon disconnection. The Nyquist plots then compare with the measured $I-V$ curve.

In this paper, the impacts of cracks appeared on PVs are studied first to get a better understanding of their failure mechanism, detrimental effects, criticality and potential risks. In this study, the most common cracked cells are mimicked by six crack scenarios; then, their effects have been reported. Second, an online technique to track the cracked cells has been proposed by investigating the AC parameter of the solar cell in the dynamic regime. The proposed technique can examine the cracked cell by injecting a sinusoidal AC signal and monitoring its voltage and current to measure the phase shift. Third, the extent to which the cracked cells act on the degraded performance of the PV panels has been studied. In this paper, experiments focusing on evaluating the output power performances of PV panel which include cracked cells are conducted. In addition, the power performance of identical PV panels, some of which are seriously cracked is presented for a different panel configuration with and without a bypass diode.

The paper is organised as follows: in Section 2, the cracked cells are reviewed, and their impact is analysed. In Section 3, the solar mathematical module is discussed, and its equations are derived. In Section 4, the proposed cracked solar cells tracking technique is discussed. In Section 5, the experiment is conducted to evaluate the performance of PV strings with different connection methods, followed by the conclusion in Section 6 .

\section{Review of impacts of different crack types on PV panel output performances}

First, the static behaviour of the PV panel is reviewed in this section. The basic theory behind the static behaviour evaluation is that the electrical isolations caused by cracks will change the optimal operation point of a PV panel, as illustrated in Fig. 1. The MPP of a normal PV cell is at the top line (blue line). However, when the cell is cracked, and the crack is large enough to cause isolation, the point will drop to the lower line (red line). If the normal PV cells and cracked cells are series connected, the total output power will drop due to the change of the operation point, and the cracked panel will operate in reverse-biased condition which causes a hot spot that may damage the panel.

A series of experimental works are conducted to investigate the impacts of different crack types on their corresponding output performances. The measurements are implemented in the laboratory where the ambient temperature is set to $25^{\circ} \mathrm{C}$. A $60 \mathrm{~W}$ solar panel which has 36 cells (Panel Model: Megavolt Solar MS$\mathrm{M} 60$ ) is used. The panel is reconfigured to form four independent strings, with each string having nine cells in series. Due to the fact that cracks are formed and aggravated through a long operation period, and not all of the crack types have significant impacts on the PV panel power generation capacity, artificial cracks are made in this experiment to mimic those serious decayed cracks. Two halogen lamps are used to simulate solar radiation. Six cases are analysed to study the effects of different types of cracked cell on the output power of the strings. The enlarged photos of a normal cell and different cracked cells are shown in Fig. 2. The scenarios are listed below:

(i) One string with no cracks (Fig. 2a): This string generates $I-V$ and $P-V$ curves under normal working condition, and it is used as a reference.

(ii) One string with one cell horizontally cracked (Fig. 2b): One cell in the second string has a hairline cut, and this cut is perpendicular to the busbar.

(iii) One string with one cell diagonally cracked between busbar (Fig. 2c): One cell in the third string is cut between the busbar, and it is at $45^{\circ}$.

(iv) One string with one cell cracked diagonally outside the busbar (Fig. 2d): This cut is similar to the previous cut, but outside the busbar (the cell effective area is reduced by $0.25 \%$ ).

(v) One string with one cell partially cracked between busbars (Fig. 2e): In this case, two cuts, parallel and close to the busbar are made. Although the cell is not fully isolated to the busbar, about half of the cell area is eliminated.

(vi) One string with one cell totally cracked (Fig. 2f): This cut is similar to the partially cracked between busbars. However, two more cuts are made to eliminate the whole cell from the string.

The measured $I-V$ and $P-V$ curves of these six cases are plotted in Figs. 3 and 4, respectively. As can be seen, the worst scenario happens when a cell is totally cracked, followed by a cell that is 

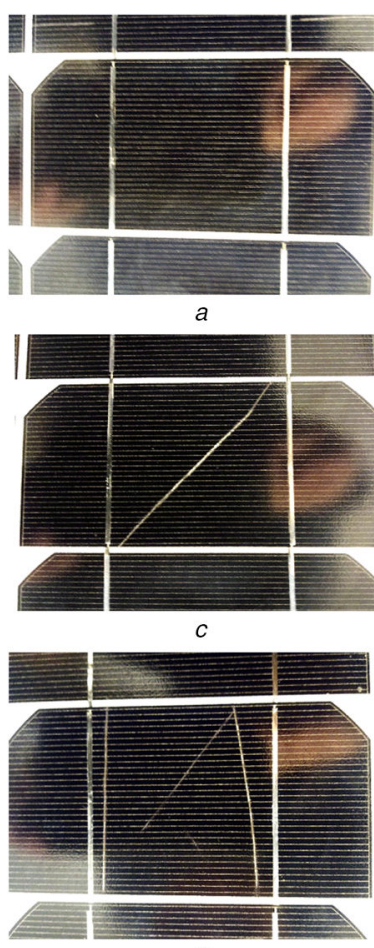

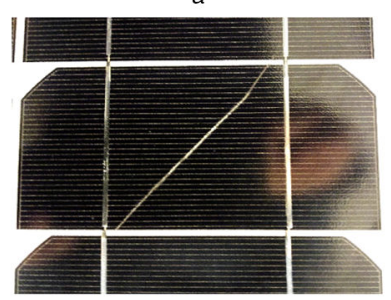

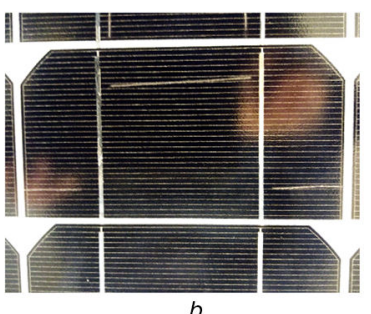
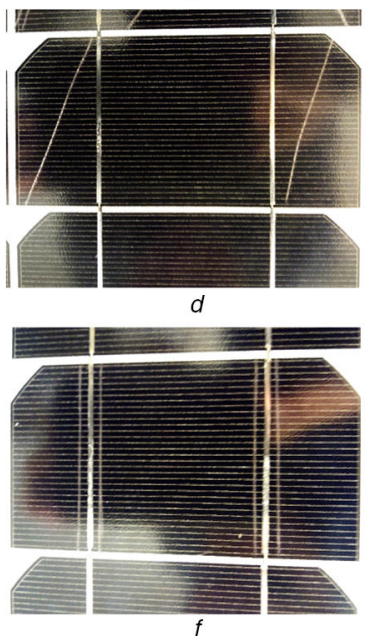

Fig. 2 Enlarged looks of a normal cell and five cracked cells in different $P V$ strings

(a) No cracks, (b) Horizontally cracked cell, (c) Diagonally cracked cell between busbar, (d) Diagonally cracked cell outside busbar, (e) Partially cracked cell between busbar, $(f)$ Totally cracked cell

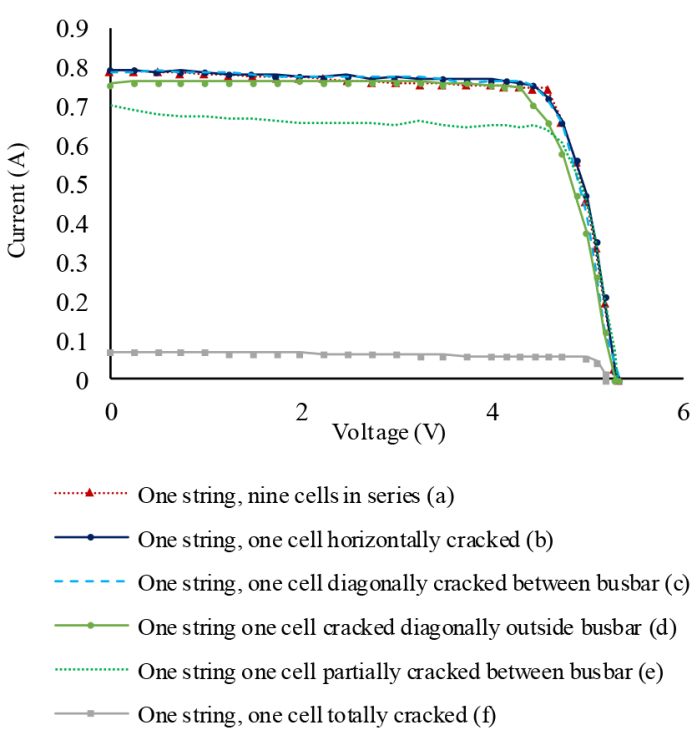

Fig. 3 I-V curves of six different PV strings

partially cracked. The totally cracked cell means the cell loses the electrical connection to the busbar while the partially cracked cell has limited effective area to generate current. Both of these two cases show a reduced current of the entire PV string. That is because of the structure of the soler cell. The cell is basically a P$\mathrm{N}$ junction and the front layer is a negative layer while the back layer is a positive one. In order to link PV cells in series, connections are made by connecting the top layer of the first cell to the bottom layer of the second cell, as shown in Fig. 5. The current flows between the two layers, hence, any cells have serious cracks will affect the entire current path. Moreover, temperature in each case is monitored, to study the potential risk of hot spot caused by cracks.

Table 1 provides a summary of the maximum power, virtual power (the short circuit current multiply by the open circuit voltage), fill factor (FF), normalised efficiency, and temperature of
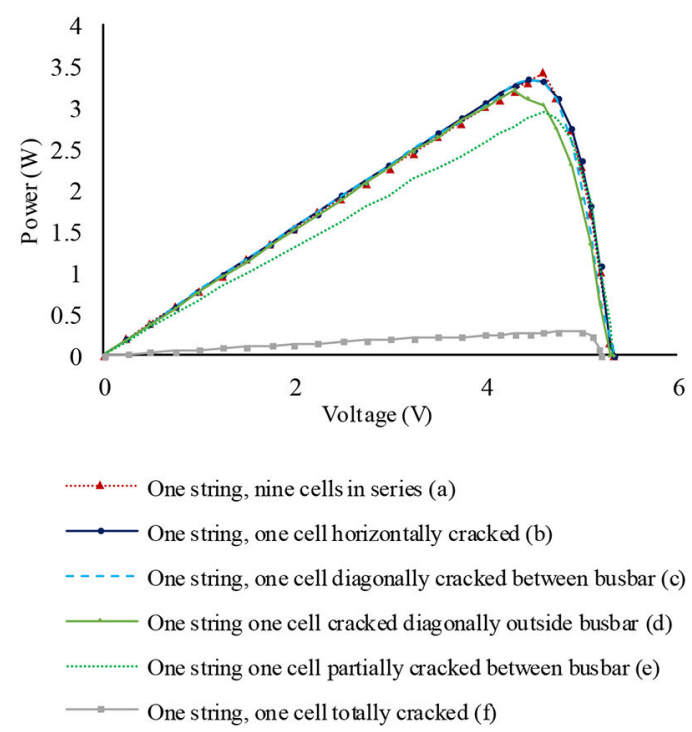

Fig. $4 P-V$ curves of six different $P V$ strings

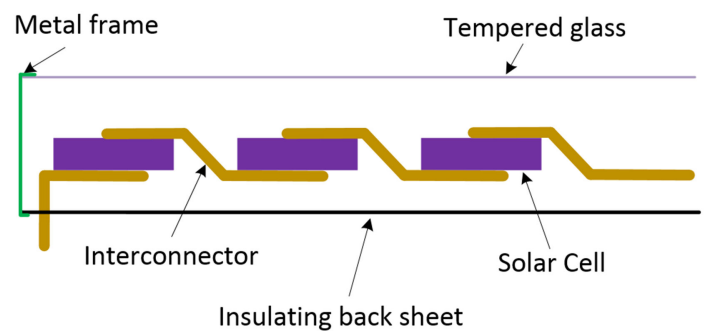

Fig. 5 PV cell physical structure

these six cases. The FF is the most important parameter that defines the quality of a PV panel. The FF value can be calculated by finding the ratio of maximum power over the virtual power, which is used to define the quality of a PV panel as described in (1). Higher FF value implies higher solar cell quality [5]. The results have shown that, with the increasing of the seriousness of a cracked cell in a PV string, the string quality, maximum power generation capability, efficiency are reduced accordingly. The room temperature is set to $25^{\circ} \mathrm{C}$, and the $\mathrm{PV}$ panel is cooled down before doing the next experiment. The temperature increases possibly due to the halogen lamps in the first case. And with the increasing of the serious level of cracks, the temperature rises accordingly. Case 6 shows the string increases to $34^{\circ} \mathrm{C}$ and the two neighbouring cells increase to $31^{\circ} \mathrm{C}$, which possibly can be developed to a hot spot.

$$
\mathrm{FF}=\frac{P_{\mathrm{mpp}}}{I_{\mathrm{sc}} V_{\mathrm{oc}}}
$$

where $P_{\text {mpp }}$ is the maximum power at the MPP, $I_{\mathrm{sc}}$ short circuit current and $V_{\mathrm{oc}}$ is the open circuit voltage.

\section{Dynamic PV modelling}

The single-diode module [16-18], as shown in Fig. $6 a$, is the most commonly used method to find the equivalent circuit of a PV cell. In most cases, the PV cells, which are arranged in an array form, are connected to switch-mode power converters to either track the MPP or regulate the output voltage. These power converters increase the harmonics penetration due to their switching frequency. The appeared ripple causes some dynamic characteristic for the solar cells. Therefore, the single-diode module becomes less accurate [19]. The PV cell is, in fact, a $\mathrm{p}-\mathrm{n}$ junction semiconductor with parasitic resistances, capacitance and inductance. The largesignal model is more useful to study the behaviour of the PV cell as the charge storage at the junction is considered under the power mismatch that can be caused by the partial shading, ageing, degradation and cell microcracks $[12,20,21]$. The large-signal

IET Renew. Power Gener., 2019, Vol. 13 Iss. 16, pp. 3002-3008 (C) The Institution of Engineering and Technology 2019 
Table 1 Summary of maximum power, virtual power, FF, efficiency and temperature of six different crack types

\begin{tabular}{lccccc}
\hline $\begin{array}{l}\text { Case study (one string with nine cells in } \\
\text { series) }\end{array}$ & Maximum power & $\begin{array}{c}\text { Visual power } \\
\text { (Ishort }{ }^{*} \text { Vopen) }\end{array}$ & FF & $\begin{array}{c}\text { Nomalised } \\
\text { efficiency }\end{array}$ & $\begin{array}{c}\text { Temperature, }{ }^{\circ} \mathrm{C} \\
\text { normal string, no cracks }\end{array}$ \\
one cell horizontally cracked & 3.410 & 4.216 & 0.8089 & 1 & 27 \\
one cell diagonally cracked between busbars & 3.343 & 4.221 & 0.7920 & 0.98034 & 29 \\
one cell cracked diagonally outside busbar & 3.338 & 4.195 & 0.7959 & 0.97891 & 29 \\
one cell partially cracked between busbar & 3.209 & 4.043 & 0.7937 & 0.94093 & 30 \\
one cell totally cracked & 2.942 & 3.722 & 0.7904 & 0.86272 & 31 \\
\hline
\end{tabular}

model shown in Fig. $6 b$ consists of a current source where the light-generated current $I_{\mathrm{ph}}$ is directly proportional to the solar irradiance, a forward-biased diode $D_{\mathrm{f}}$, a shunt resistance $R_{\mathrm{sh}}$, a series resistance $R_{\mathrm{S}}$ and a parallel capacitance $C_{\mathrm{p}}$. The lightgenerated current $I_{\mathrm{ph}}$ is given as

$$
I_{\mathrm{ph}}(G, T)=\left[I_{\mathrm{sc}, \mathrm{n}}+K_{i}\left(T-T_{\mathrm{n}}\right)\right] \frac{G}{G_{\mathrm{n}}}
$$

where the $I_{\mathrm{sc}, \mathrm{n}}$ is the short-circuit light-generated current at the nominal condition (a standard testing condition usually $25^{\circ} \mathrm{C}$ and $\left.1000 \mathrm{~W} / \mathrm{m}^{2}\right), K_{i}$ is the temperature coefficient of the short circuit current, $T$ is the tested temperature, $G$ is the tested irradiance and $T_{\mathrm{n}}$ and $G_{\mathrm{n}}$ are temperature and irradiance at nominal condition, respectively [13]. According to the diode equations the diode thermal voltage at different temperature is given as

$$
V_{\mathrm{t}}(T)=\frac{k T}{q} N_{\mathrm{s}}
$$

where $k$ is Boltzmann's constant, $q$ is an electron charge, and $N_{\mathrm{s}}$ is the number of series cells. The diode current is given as

$$
I_{\mathrm{d}}=I_{0}\left[\exp \left(\frac{V_{\mathrm{d}}}{n V_{\mathrm{t}}}\right)-1\right]=I_{0}\left[\exp \left(\frac{V_{\mathrm{pv}}+I_{\mathrm{pv}} R_{\mathrm{s}}}{n V_{\mathrm{t}}}\right)-1\right]
$$

where $I_{0}$ is the diode reverse saturation current and $n$ is the ideality factor of the solar cell diode that ranges from 1 to 2 . According to Ohm's law, the current flows in the shunt resistor is given as

$$
I_{\mathrm{sh}}=\frac{V_{\mathrm{d}}}{R_{\mathrm{sh}}}=\frac{V_{\mathrm{pv}}+I_{\mathrm{pv}} R_{\mathrm{s}}}{R_{\mathrm{sh}}}
$$

By considering the above equation, the solar cell current is expressed as

$$
\begin{aligned}
& I_{\mathrm{pv}}=I_{\mathrm{ph}}-I_{\mathrm{d}}-I_{\mathrm{sh}} \\
& I_{\mathrm{pv}}=I_{\mathrm{ph}}-I_{0}\left[\exp \left(\frac{V_{\mathrm{pv}}+I_{\mathrm{pv}} R_{\mathrm{s}}}{n V_{\mathrm{t}}}\right)-1\right]-\frac{\left(V_{\mathrm{pv}}+I_{\mathrm{pv}} R_{\mathrm{s}}\right)}{R_{\mathrm{sh}}}
\end{aligned}
$$

The value of the parallel capacitor changes in accordance with different operating points of the solar cell as it is described in

$$
I_{C_{\mathrm{p}}}=C_{\mathrm{p}} \frac{\mathrm{d} V_{\mathrm{d}}}{\mathrm{d} t}
$$

According to the above study of the solar cell behaviour in the static regime and its derivative (2)-(7), it is notable that it is not possible to catch any change in the parasitic capacitance that can be caused by the solar cells again and degradation. Therefore, the dynamic regime and associated AC parameters become very attractive to study and determine the behaviour of the solar cell. The AC small-signal of the equivalent large-signal model that is shown in Fig. $6 b$ is depicted in Fig. 7, and its impedance $Z$ is presented in (8). It is clear that the effect of the parallel capacitor $C_{\mathrm{p}}$ appears by studying the dynamic regime

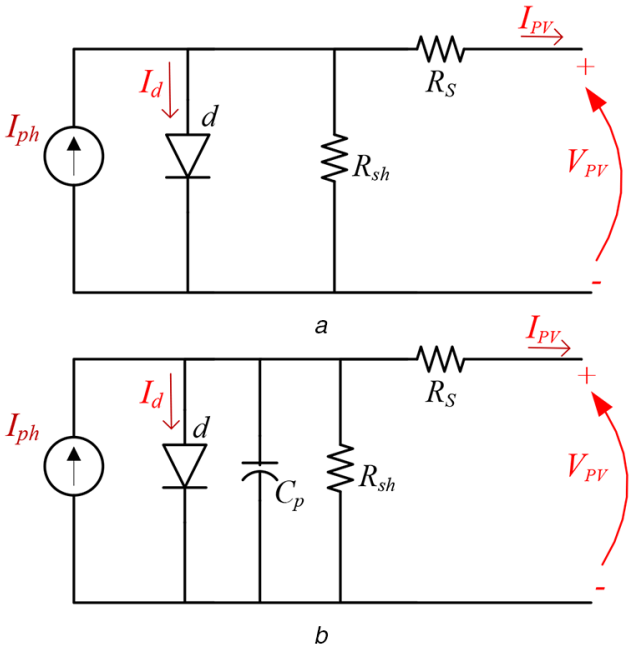

Fig. 6 Equivalent circuit of solar pv module (a) Single-diode module, (b) Large-signal model

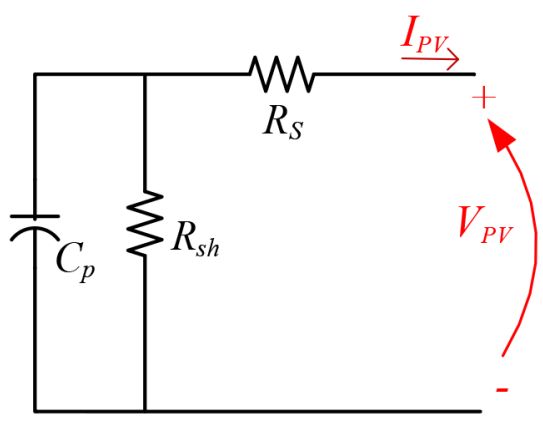

Fig. 7 AC small-signal solar cell model

$$
Z=\left[R_{\mathrm{s}}+\frac{R_{\mathrm{sh}}}{1+\left(\omega C_{\mathrm{p}} R_{\mathrm{sh}}\right)^{2}}\right]-\mathrm{j}\left[\frac{\omega C_{\mathrm{p}} R_{\mathrm{sh}}^{2}}{1+\left(\omega C_{\mathrm{p}} R_{\mathrm{sh}}\right)^{2}}\right]
$$

The parallel capacitor $C_{\mathrm{p}}$ is the sum of the diffusion capacitance $C_{\mathrm{d}}$ and the transition capacitance $C_{\mathrm{t}}$. In fact, these capacitances are non-linear values depending on the operating point voltage, and it can give vital information about the solar cell [22]. According to $[22,23]$, the transition capacitance is caused by the separation of charges in the space charge region and is given by

$$
C_{\mathrm{t}}=\left|\frac{\mathrm{d} Q}{\mathrm{~d} V_{\mathrm{a}}}\right|=\frac{b}{\sqrt{V_{\mathrm{j}}-V_{\mathrm{a}}}}=A \sqrt{\frac{N q \epsilon_{0} \epsilon_{\mathrm{r}}}{2\left(V_{\mathrm{j}}-V_{\mathrm{a}}\right)}}
$$

where $a$ constant $b$ depends on the solar cell, $V_{\mathrm{j}}$ is the junction voltage, $V_{\mathrm{a}}$ is the applied voltage, $A$ is the area of the solar cell, $e$ is the elementary charge, $\epsilon_{0}$ is the permittivity of free space, $\epsilon_{\mathrm{r}}$ represents the relative permittivity of the solar cell material, $N_{\mathrm{D}}$ and $N_{\mathrm{A}}$ are the doping concentration in $\mathrm{cm}^{3}$ in the $n$ and $p$ regions, respectively. The value of the doping concentration, junction voltage and constant $b$ are defined as 


$$
\begin{gathered}
N=\frac{N_{\mathrm{D}} N_{\mathrm{A}}}{N_{\mathrm{D}}+N_{\mathrm{A}}} \\
V_{\mathrm{j}}=\frac{k T}{q} \ln \left[\frac{N_{\mathrm{D}} N_{\mathrm{A}}}{N_{\mathrm{i}}^{2}}\right] \\
b=A \sqrt{\frac{N q \epsilon_{0} \epsilon_{\mathrm{r}}}{2}}
\end{gathered}
$$

where $N_{\mathrm{i}}$ is the intrinsic concentration of electrons and holes for the base semiconductor. The diffusion capacitance $C_{\mathrm{d}}$ is notable during forward-bias of the $\mathrm{p}-\mathrm{n}$ junction, and its value depends on the frequency and voltage according to [22]

$$
C_{\mathrm{d}}=\frac{\tau q}{2 k T} I_{0} \exp \left(\frac{q V_{\mathrm{a}}}{n k T}\right), \omega \tau<<1
$$

where $\tau$ is a minority carrier of lifetime. According to [24-26] minority carrier lifetime is highly degraded by the solar cell ageing during outdoor exposure. Thus, the electrical parameters of the solar cell are more likely to change with time. Accordingly, the cracked and aged solar cell case a change in parallel capacitors value associated with the solar cell during the dynamic regime. This behaviour can be used to detect the cracked solar cell, and it can be achieved by operation the solar cell at a different frequency.

\section{AC small-signal to investigate cracked cells}

\subsection{Experiment setup}

The PV modules show non-linear parallel capacitance when it is connected to high-frequency power converters $[12,19]$. In this experiment, the dynamic behaviour of the normal solar cell is investigated and compared with a cracked cell to prove that the crack and ageing affect the solar cell parallel capacitor. Another objective for this experiment is to prove that the crack diagnosis of the PV cell can be carried out by investigating the dynamic performance of the PV cells while it is connected online, without the need of physical inspection for the solar panels. Fig. 8 shows the equipment setup for this experiment.

In this experiment, three of the PV strings that are used in the first experiment are used with the same cracked arrangements namely; normal string with no cracks, string with one cell cracked between the busbar and string with one cell totally cracked. A function generator is directly connected to the PV module where a sinusoidal signal at $1 V_{p-p}$ and the overall DC offset equals the voltage at the MPP at $4.7 \mathrm{~V}$, is injected to the PV cells. An oscilloscope (Tektronix TBS2000) is used to capture the injected voltage waveform and the reflected current while the frequency of the sinusoidal signal is swept from $1 \mathrm{~Hz}$ to $1 \mathrm{MHz}$. The solar panel was arranged in a way that it does not expose to any radiation but responding only to the injected AC signal.

\subsection{Experimental results}

The injected voltage and the reflected current waveforms are captured and analysed while performing a frequency sweep. Fig. 9 shows the waveforms of the injected voltage and the reflected current for the string with normal cells and the string with one cell totally cracked at $100 \mathrm{kHz}$ frequency. Results show that the current leads the voltage which implies that the equivalent circuit of the solar cell is no longer of purely resistive nature as it is derived in the single-diode module, particularly when it is connected to switching power converters. Nevertheless, the waveform implies that the equivalent circuit of the solar cell behaves as a capacitive circuit. According to the recorded waveform, the current leads the voltage by $27^{\circ}$ for the normal string while it increases by $11.66^{\circ}$ to become $38.66^{\circ}$ for the string with one cell totally cracked.

The solar cell impedance and the phase shift are calculated in order to obtain the Bode plot. The Bode plot for the three strings is presented in Fig. 10. It is clearly illustrated from the plot that the impedance increases for the PV strings with microcracks. This

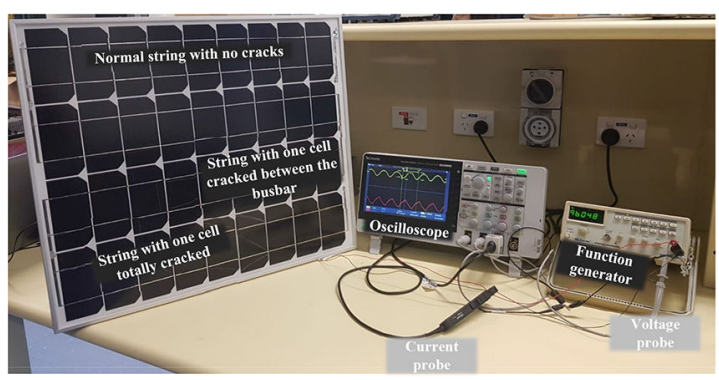

Fig. 8 Experiment setup for testing dynamic behaviour of the solar panel with and without cracked cells
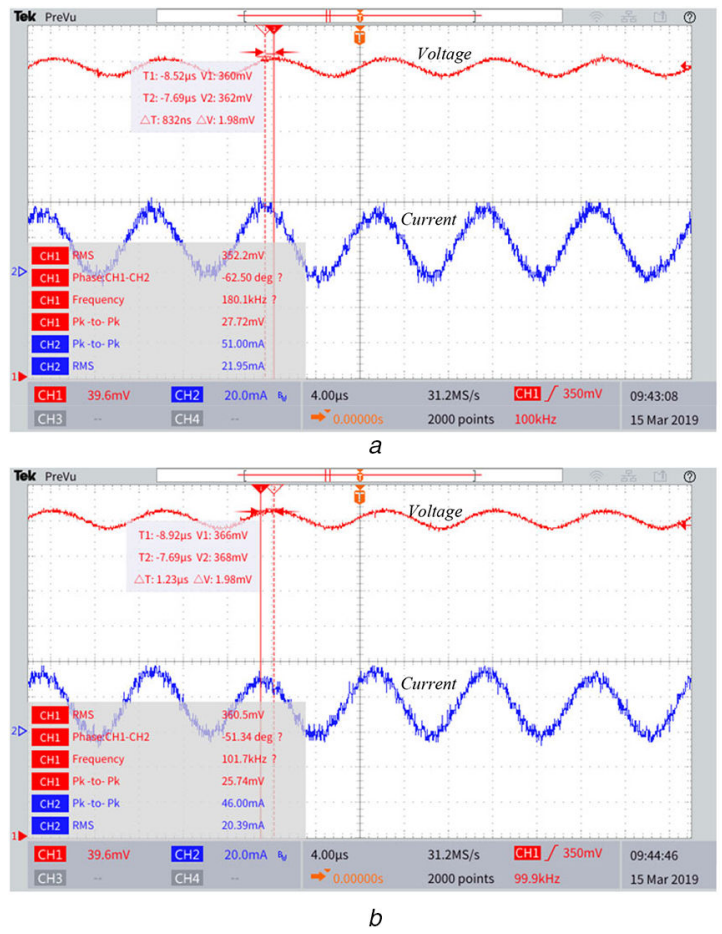

Fig. 9 Waveform for the injected voltage and the reflected current (a) String with normal cells, (b) String with one cell totally cracked, at $100 \mathrm{kHz}$ frequency

provides the evidence for the drop of the power generated from the PV string if there is at least one cell cracked. The phase response also shows a clear indicator for a cracked string at the resonant frequency $(\approx 120 \mathrm{kHz})$. For other scenarios where the normalised efficiency of the strings is $>94 \%$ (Table 1), the cracked solar panel demonstrated small capacitive behaviour.

\section{Performance evaluation of PV panel and system with different connection methods}

In order to investigate the effect of the cracks further, and to confirm that the cracks affect the behaviour of the solar cell regardless of its brand and manufacture, the previous experiments (Sections 2 and 4) have been reperformed by using a $20 \mathrm{~W}$ solar panel with 36 cells (Panel Model: Powertech ZM9055). The experiment results show that the output power performance similar to the one in the previous experiment. In addition to studying how the cracked cells affect individual PV string output power, the following experimental work investigates and compares the performance of three groups of experiments as described below:

(i) Evaluation of output performances of a normal PV panel, a panel with two cracked cells and a panel with two shaded cells.

(ii) Investigation and comparison of performances among three different PV panel strings, namely, two normal PV panels connected in series, two PV panel connected in series with one 

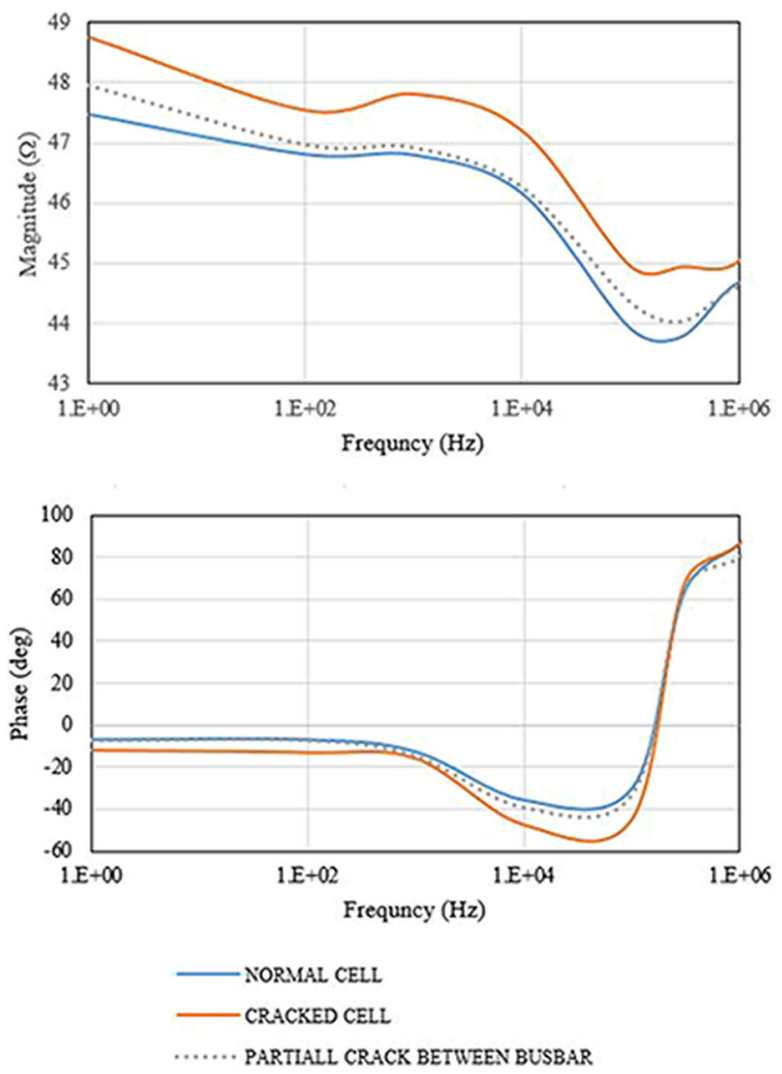

Fig. 10 PV AC small-signal model bode plot
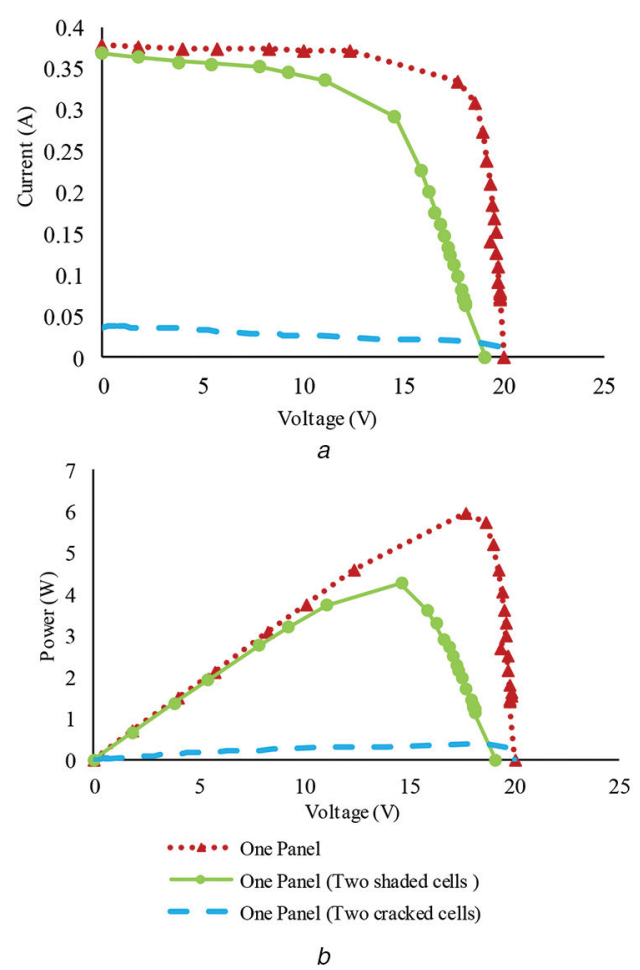

Fig. 11 The performance of one normal panel, one panel with two shaded cells and one panel with two cracked cells

(a) $\mathrm{I}-\mathrm{V}$ curve, (b) $\mathrm{P}-\mathrm{V}$ curve

seriously cracked panel, and two PV panels connected in series with one panel seriously cracked and bypass diode is used.

(iii) Investigation and comparison of output performance between two PV panels connected in parallel and two PV panels connected in parallel with one panel having serious cracked cells. It is worth noting that the bypass diode which is adopted to mitigate the crack impacts is also studied and compared.

IET Renew. Power Gener., 2019, Vol. 13 Iss. 16, pp. 3002-3008

(c) The Institution of Engineering and Technology 2019
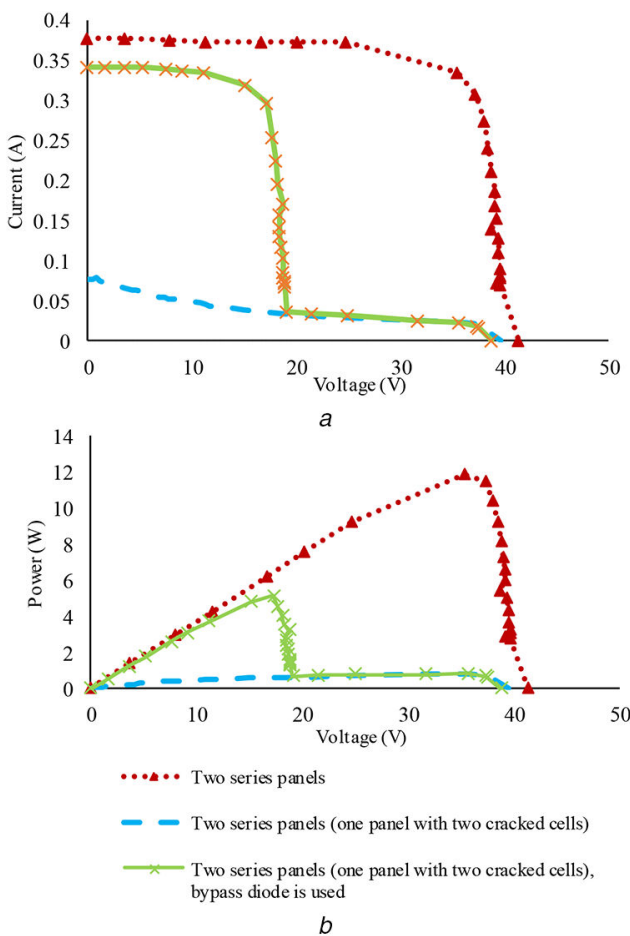

Fig. 12 The performance of two panels connected in series, two panels connected in series with one cracked, and two panels connected in series with one cracked and a bypass diode is connected (a) $\mathrm{I}-\mathrm{V}$ curve, (b) $\mathrm{P}-\mathrm{V}$ curve

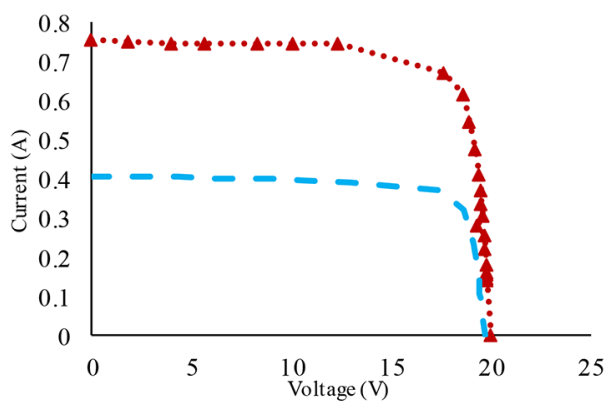

a

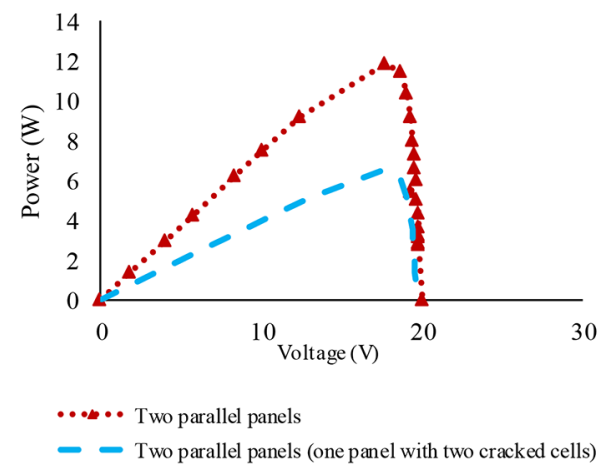

$b$

Fig. 13 The performance two panels connected in parallel and two panels connected in parallel with one cracked

(a) $\mathrm{I}-\mathrm{V}$ curve, (b) $\mathrm{P}-\mathrm{V}$ curve

The experimental results of the aforementioned three groups are shown in Figs. 11-13, respectively. As can be observed in Fig. 11, the detrimental impact of the cracks is more critical than the partial shading effect when the cells are seriously cracked. In Fig. 12, the results indicate that the seriously cracked panel clamps the current of the PV string, and hence, significantly reducing the generation power. In addition, the extra bypass diode can effectively mitigate this phenomenon. The results in Fig. 13 show that the operation of the normal panel is not affected by the cracked one in the parallel- 
connected PV string, and the bypass diode is useless with the parallel connection. However, the overall power is still low.

According to the previous investigation and study, the crack greatly affects the performers of the solar cell, and it gets greater when the cells form a string or a panel. When it comes to the solar system, one panel with a few cracked cells can drop the power generated by $90 \%$. Even with bypass diode, the power can drop by $60 \%$. Hence it presents an important need to track the cracked cells to improve the power quality of the solar system.

\section{Conclusion}

In this paper, the failure mechanism, detrimental effects, criticality and potential risks of cracks on independent PV strings are experimentally reviewed by studying the impacts of different crack types. The results verify that the loss of electrical connection between PV cell and busbar would cause a great reduction of the entire PV string power generation capability. Moreover, a crack detection technique is proposed by studying the dynamic regime of the solar cell in addition to investigating the AC behaviour of the normal solar string and the cracked solar strings with different severities. The result indicates that the fully cracked strings show a higher resistive and capacitive characteristics at high frequency than others. The experiment result shows that the current leads the voltage by $27^{\circ}$ for the normal string while it increases by $11.66^{\circ}$ to become $38.66^{\circ}$ for a string with one cell totally cracked. Accordingly, the proposed crack detection technique observing the change in the dynamic behaviour of the solar panel is regarded as a promising technique to track the cracked, ageing and shaded cell to improve overall solar system efficiency and reliability.

A comparison between the series and parallel connected PV panel strings are given. Bypass diodes are recommended to be added to the PV panel string to mitigate the current reduction by the seriously cracked cells. To increase the solar cell lifetime, improve the solar system efficiency and reliability, the proposed crack detection method could be implemented by the solar cell operating converter that may be used for the MPP tracking MPPT, or output voltage regulation. By detecting the cracked cell, hot spot will be prevented before damaging the solar cell permanently.

\section{Acknowledgments}

The M.A.-S. gratefully acknowledges the Scholarship received towards his $\mathrm{PhD}$ from the Al-Hussein Bin Talal University (Ahu/ 4/2047). This research was funded partially by the Australian Government through the Australian Research Council (Discovery Projects DP180100129).

\section{References}

[1] Sharp: 'Solar modules', NU-RC300 (300 W), datasheet, Availabe at https:// www.sharp.co.uk/cps/rde/xchg/gb/hs.xsl/-/html/product-details-solarmodules-2189.htm?product=NURC300

[2] Solar Technology Internation Ltd: 'Mono \& poly-crystalline (12 volt) silicone solar cell modules', 5WP-150WP,Availabe at http:// www.solartechnology.co.uk/solar-panels/pv-logic-panels/standard-solarpanels

[3] Dhimish, M., Holmes, V., Dales, M., et al.: 'Effect of micro cracks on photovoltaic output power: case study based on real time long term data measurements', IET Micro Nano Lett., 2017, 12, (10), pp. 803-807
[4] Dhimish, M., Holmes, V., Mehrdadi, B., et al.: 'The impact of cracks on photovoltaic power performance', J. Sci.: Adv. Mater. Devices, 2017, 2, (2), pp. 199-209. 10.1016/j.jsamd.2017.05.005

[5] Kontges, M., Kurtz, S., Jahn, U., et al.: 'Performance and reliability of photovoltaic systems: Subtask 3.2: Review of failures of photovoltaic modules', IEA PVPS Final Report, 2014

[6] Kontges, M., Kajari-Schr oder, S., Kunze, I., et al.: 'The risk of power loss in crystalline silicon based photovoltaic modules due to micro-cracks', Sol. Energy Mater. Sol. Cells, 2011, 95, pp. 1131-1137

[7] Kajari-Schroder, S., Kunze, I., Kontges, M.: 'Criticality of cracks in PV modules', Energy Procedia, 2012, 27, pp. 658-663

[8] Gade, V., Shiradkar, N., Paggi, M., et al.: 'Predicting the long term power loss from cell cracks in PV modules'. 2015 IEEE 42nd Photovoltaic Specialist Conf. (PVSC)., New Orleans, LA, 2015, pp. 1-6

[9] Cheng, T., Al-Soeidat, M., Lu, D.D., et al.: 'Experimental study of PV strings affected by cracks', J. Eng., 2019, 2019, (18), pp. 5124-5128

[10] Dolara, A., Leva, S., Manzolini, G., et al.: 'Investigation on performance decay on photovoltaic modules: snail trails and cell microcracks', IEEE $J$ Photovoltaics., 2014, 4, (5), pp. 1204-1211

[11] Chenvidhya, D., Kirtikara, K., Jivacate, C.: 'PV module dynamic impedance and its voltage and frequency dependencies', Sol. Energy Mater. Sol. Cells. 2005, 86, (2), pp. 243-251

[12] Kim, K.A., Xu, C., Lei, J., et al.: 'A dynamic photovoltaic model incorporating capacitive and reverse-bias characteristics', IEEE J. Photovoltaics, 2013, 3, (14), pp. 1334-1341

[13] Villalva, M.G., Gazoli, J.R., Filho, E.R.: 'Comprehensive approach to modeling and simulation of photovoltaic arrays', IEEE Trans. Power Electron., 2009, 24, (5), pp. 1198-1208. doi: 10.1109/TPEL.2009.2013862

[14] Kim, K.A., Seo, G., Cho, B., et al.: 'Photovoltaic hot-spot detection for solar panel substrings using AC parameter characterization', IEEE Trans. Power Electron.., 2016, 31, (2), pp. 1121-1130

[15] Katayama, N., Osawa, S., Matsumoto, S., et al.: 'Degradation and fault diagnosis of photovoltaic cells using impedance spectroscopy', Sol. Energy Mater. Sol. Cells., 2019, 194, pp. 130-136

[16] Hejri, M., Mokhtari, H.: 'On the comprehensive parametrization of the photovoltaic (PV) cells and modules', IEEE J. Photovoltaics, 2017, 7, (1), pp. 250-258

[17] Batzelis, E.I., Kampitsis, G.E., Papathanassiou, S.A., et al.: 'Direct MPP calculation in terms of the single-diode PV model parameters', IEEE Trans. Energy Convers., 2015, 30, (1), pp. 226-236

[18] Shongwe, S., Hanif, M.: 'Comparative analysis of different single-diode PY modeling methods', IEEE J. Photovoltaics, 2015, 5, (3), pp. 938-946

[19] Benavides, N.D., Chapman, P.L.: 'Modeling the effect of voltage ripple on the power output of photovoltaic modules', IEEE Trans. Ind. Electron., 2008, $\mathbf{5 5}$ (7), pp. 2638-2643

[20] Suskis, P., Galkin, I.: 'Enhanced photovoltaic panel model for MATLABsimulink environment considering solar cell junction capacitance'. IECON 2013 - 39th Annual Conf. IEEE Industrial Electronics Society, Vienna, 2013 pp. $1613-1618$

[21] Wang, W., Liu, A.C., Chung, H.S., et al.: 'Fault diagnosis of photovoltaic panels using dynamic current-voltage characteristics', IEEE Trans. Power Electron., 2016, 31, (2), pp. 1588-1599

[22] Cotfas, D., Cotfas, P., Kaplanis, S.: 'Methods and techniques to determine the dynamic parameters of solar cells: review', Renew. Sust. Energy Rev, 2016, 61, pp. 213-221. 10.1016/j.rser.2016.03.051

[23] Kumar, S., Sareen, V., Batra, N., et al.: 'Study of C-V characteristics in thin $\mathrm{n}+$-p-p + silicon solar cells and induced junction n-p-p + cell structures', Sol. Energy Mater. Sol. Cells, 2010, 94, (9), pp. 1469-1472. 10.1016/ j.solmat.2010.03.019

[24] Tobnaghi, D.: 'Recovery of the electrical parameters of degraded solar cells by ultrasonic treatment', J. Electr. Eng. Technol., 2016, 11, (5), pp. $1337-$ 1341. 10.5370/jeet.2016.11.5.1337

[25] Samieipour, A., Neubauer, C., Oueslati, S., et al.: 'Ageing of kesterite solar cells 2: impact on photocurrent generation', Thin Solid Films, 2019, 669, pp. 509-513. Available: 10.1016/j.tsf.2018.11.044

[26] Adhyaksa, G., Veldhuizen, L., Kuang, Y., et al.: 'Carrier diffusion lengths in hybrid perovskites: processing, composition, aging, and surface passivation effects', Chem. Mater., 2016, 28, (15), pp. 5259-5263. 10.1021/ acs.chemmater.6b00466 